\title{
Safe as houses? The risks of radon
}

\section{John Fremlin}

Radon and its Decay Products: Occurrence, Properties, and Health Effects. Edited by Philip K. Hopke. American Chemical Society: 1987. Pp.609. \$89.95, £63.85.

Indoor Radon and its Hazards. Edited by David Bodansky, Maurice A. Robkin and David R. Stadler. University of Washington Press: 1987. Pp.147. Hbk \$20, pbk\$9.95.

Environmental Radon. Edited by C. Richard Cothern and James E. Smith, Jr. Plenum: 1987. Pp.363. \$55, £66.

Radon and its Decay Products in Indoor Air. Edited by William W. Nazaroff and Anthony V. Nero, Jr. Wiley: 1988. Pp.518. £65, \$75.

Health Risks of Radon and Other Internally Deposited Alpha-Emitters. BEIR IV. National Academy Press: 1988. Pp. 602. Hbk \$51, pbk \$39. In Europe distributed by Wiley, $h b k £ 36.45$, pbk£27.90.

THE general lack of public concern about the health risks caused by the natural radioactive gas radon is one of the odder features of modern life. Whatever the reasons for that indifference, little commensurate with the real importance of the subject has been published in the West. With the appearance of these five books, this curious and undesirable silence has now been broken. All are aimed at professionals who are familiar with the properties of radioactive materials and are interested in radiation hazards.

Each of the first four volumes consists of articles written by various experts. That edited by Hopke, for example, includes a useful overview by Hopke himself, and a series of updated papers from an American Chemical Society symposium held in April 1986. Unusually for a book with this provenance, the result is not only authoritative but readable and coherent.

BEIR IV differs in two main ways from the other volumes. First, the individuals who produced the text remain anonymous, but were members of a long-standing committee of 12 medical, radiological and epidemiological experts who were chosen "for their special competence and with regard to appropriate balance".
Secondly, it deals with other alpha emitters, ingested rather than inhaled, as well as with radon and its short-lived decay products. These other alpha emitters will usually be found in other organs than the bronchi and lungs and many of them have long half-lives. Most of the discussion of sub-cellular damage caused by alpha particles from plutonium, for example, applies also to the damage caused by alpha particles from the radon progeny. This receives scant attention in the other books apart from Hopke's.

The first practical requirement in looking at health hazards caused by radon is to determine the quantity of the progeny being inhaled. Several quick and effective methods, some of which need expensive equipment, are described in each of the first four books (in some detail in Hopke). Such methods are valuable for preliminary surveys, and for comparison of the hazards in different areas, but are inadequate for the estimation of the average risks to the population. The concentrations of radon progeny in any particular room on any particular day depend on whether doors and windows are open or shut; alter every time someone opens the door; vary between winter and summer; and depend on the difference between indoor and outdoor temperature.

Hopke's book describes several national radon surveys employing different measurement techniques, including that used in the systematic British study in which C39 plastic alpha-track detectors were placed for two successive continuous six-month periods in 2,000 homes. From this, an average annual effective doseequivalent of 43 millirems was deduced assuming 75 per cent mean occupancy.

A contributor to Cothern and Smith describes a system in which six separate measurements are made at least four weeks apart, each of 100 hours duration, with care to ensure similar ventilation conditions. This was quite appropriate for following the decommissioning of uranium mill sites for which it was developed, but not for long continuous periods in large numbers of houses. The use of plastic alpha detectors, also covered briefly, is much more suitable.

The book of Bodanksy et al. includes an account of such detectors used for 30 days at a time. These can of course be used one after another to cover a year or more, but the importance of obtaining measurements all round the year is not stressed. Thermoluminescent detectors are also mentioned; these have their advantages, but are less sensitive and add to their record the doses from cosmic rays and gamma rays from the ground. Nazaroff and Nero has a brief but adequate article on the etched-track method, together with descriptions of several other methods too expensive for use over long periods in large numbers of houses. BEIR IV does not cover the measurement of indoor radon at all.

Having assessed the doses received, the next step is to estimate the health risk. The method adopted by the International Commission for Radiological Protection (ICRP) is to use the numbers of excess

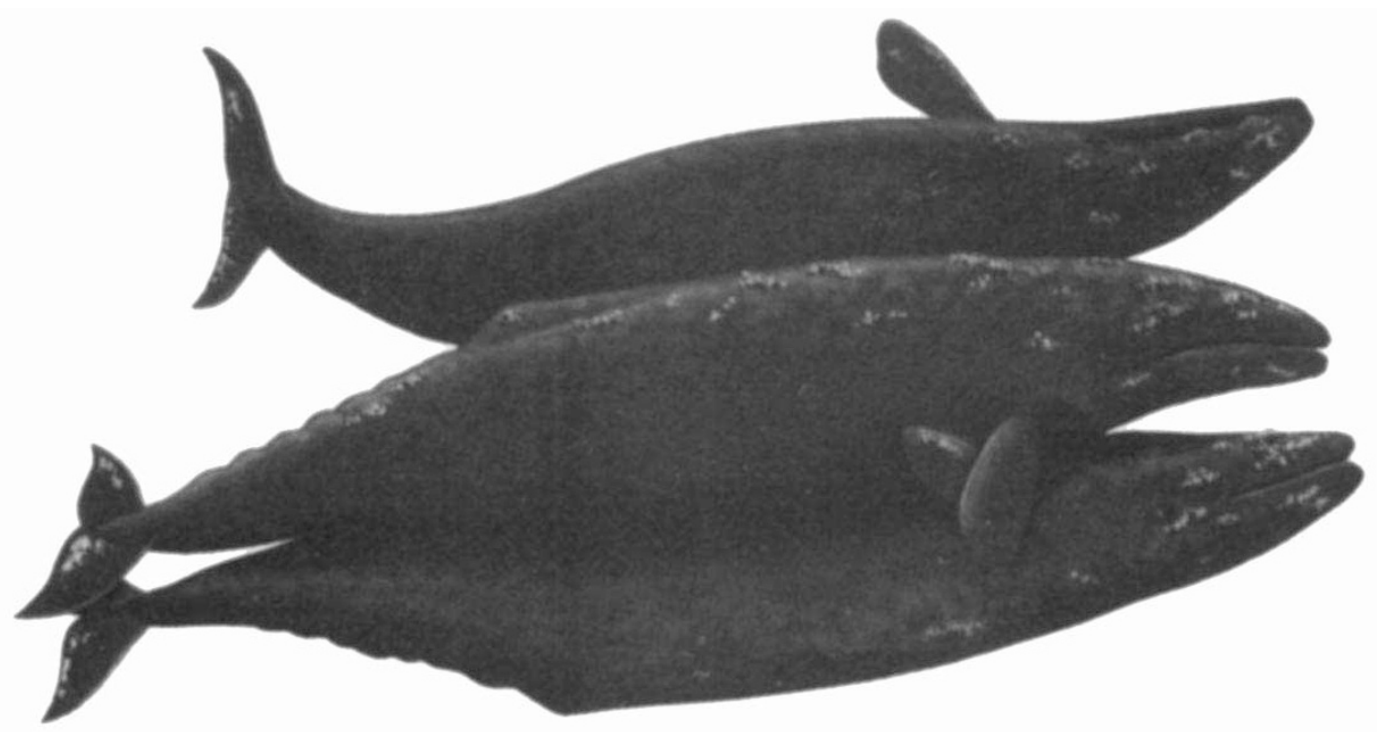

Menage à trois - mating for the grey whale Eschrichtius robustus is complex and elaborate. Only one male is involved in the actual mating; the other takes an upright position on the far side of the female, acting as a prop or wedge. The picture is taken from Lyall Watson's Whales of the World, just reissued by Hutchinson, price 111.95 . 